\title{
Electric or Hydraulic Energy Recovery Systems in a Reach Truck- A Comparison
}

\author{
Tatiana Minav1,* - Henri Hänninen ${ }^{1}$ - Antti Sinkkonen ${ }^{1}$ - Lasse Laurila ${ }^{2}$ - Juha Pyrhönen ${ }^{2}$ \\ 1 Aalto University, School of Engineering, Department of Engineering Design and Production, Finland \\ 2 Lappeenranta University of Technology, LUT Energy, Finland
}

In this paper, electric and hydraulic regeneration methods of recovering potential energy from an electro-hydraulic forklift truck are studied. Two similar forklift setups equipped with either electric or direct hydraulic energy storage are compared. In the first setup, the forklift lifting system is controlled directly with an electric servomotor drive. The servomotor drives a hydraulic pump capable of also operating as a hydraulic motor during lowering motion. In the second setup, the hydraulically operated forklift is equipped with an energy recovery system consisting of pressure accumulators for storing energy and a hydraulic digital valve package for precise leakage free flow control. This paper describes the arrangements of the experimental setups. The results of the proposed systems are then compared from the energy efficiency point of view. Energy-savings ratios for electric and hydraulic test systems were calculated for different fork velocities and payloads.

Keywords: digital flow control unit, electric energy recovery, energy storage, forklift, hydraulic energy recovery, hydraulics, lead-acid battery, hydraulic accumulator, permanent magnet synchronous machine, reach truck, supercapacitor

\section{O INTRODUCTION}

Globally, energy efficiency and energy savings have become important practical research topics in nonroad mobile machinery [1] and [2]. In [3] and [4] energy saving lifting hydraulic systems and control techniques [5] have already been suggested. However, energy savings are still very important in non-road mobile machine applications, e.g. in excavators [6] and [7] and in machines operated purely by accumulatorstored electric energy [8] and [9]. In order to reduce the energy consumption of a machine, either the efficiencies of the components have to be improved or energy that is otherwise lost in the process has to be utilized by regeneration. In many cases the latter can be accomplished most advantageously by reusing the kinetic or potential energy of the machine or its subsystem [10] and [11]. Depending on the system and process in question, the utilization energy recovery can lead to significantly lower overall energy consumption and, with mobile machines, to longer operating times. [12] and [13]

When considering regeneration of energy, the work cycles in which forklifts often operate include bidirectional material or payload transfers, which provide an opportunity for efficient recovery of potential energy. In this study, reach trucks (a subtype of forklifts) are modified to allow energy recovery from the payload of the mast's lifting/lowering function. In the case of the other functions of the machine, there is no potential energy to be recovered, and kinetic energy levels are too low for any feasible recovery system.
There are several base technologies on which to build a recovery system; thermal, mechanical (i.e. fly-wheel or counterweight based recovery systems), electric or hydraulic. This study focuses on the last two types. A well-established method of recovering energy in mobile working machines is an electric recovery system. This system type usually consists of an electric motor/generator, an inverter, possibly a DC/DC converter, a battery, and also, in some cases, an electric double-layer capacitor (EDLC) [14]. The advantages of this kind of system are control flexibility, compactness, efficient control, and fairly high, energy efficiency [15].

With regard to the mast operations of a hydraulic reach truck, another well-known option is to use a direct or indirect hydraulic recovery system. In an indirect hydraulic storage system consisting of a hydraulic motor-pump, a controllable hydraulic pumpmotor, and a hydraulic accumulator, the flexibility of control is as good as that of electric recovery. This system first converts the hydraulic energy into mechanical and then back to hydraulic energy, requiring as many conversions as the electric storage system. In this paper, however, the direct hydraulic recovery system is compared with the electric recovery system. The direct hydraulic recovery system removes the need for energy conversions from the hydraulic to the electric form in the recovery phase and vice versa in the regenerating phase.

A direct application of the hydraulic accumulator has more limiting factors than the indirect recovery system [16] and [17]. The utilization of this type of system requires two flow control edges in the recovery phase in order to maintain controllability 
of mast velocity. This is achieved by utilization of a digital valve package (DFCU).

This study compares electric and direct hydraulic recovery systems with each other in terms of energy efficiency. The operational characteristics of both systems are also analyzed.

\section{TEST SETUPS}

This section describes the studied system setups, which includes a description of energy evaluation and work cycle. As two different setups were used, an electric recovery setup was located at the Lappeenranta University of Technology, and a hydraulic recovery setup at Aalto University.

\subsection{Electric Recovery System Setup}

The original non-regenerative $\mathrm{AC}$ electric drive and the hydraulic system of the Humanic HS-16F5400 forklift were replaced with the schematics shown in Fig. 1. The electric motor servo drive directly controls the fixed displacement hydraulic pump speed and thereby the position of the hydraulic cylinder piston instead of a traditional proportional valve. The twoway normally closed poppet valve is used as a safety valve, which prevents the load from dropping in the case of a failure. For lifting, the hydraulic pump produces a flow depending on the rotational speed of the servomotor. While lowering a mass, the potential energy forces the hydraulic machine to rotate as a motor, and the electric machine acts as a frequencyconverter-controlled generator [18]. The converter controls the generator torque and actively rectifies the generated electric energy to the DC link. Because of the relatively short lowering period (around 10 s), recharging of conventional lead acid batteries is considered inefficient [19]. For energy measuring purposes, a brake resistor was used as the "energy storage". At the moment, super capacitors seem to be the most suitable solution for fast recharging. The measured super capacitor charge-discharge cycle efficiency of $99 \%$ [4] will be used to estimate the cycle efficiency of the future system equipped with electrical energy storage. In [4], the measured voltage and current signals of the forklift electric recovery setup were used for the super capacitor efficiency measurements. In the forklift electrical energy recovery test setup, a control program was created to control both the electrical and hydraulic parts of the forklift system [20].

The instrumentation of the system covers measurement devices for pressures, rotational speed, torque, load position, phase voltages and currents, and DC voltage and DC current. The energy consumption in this paper was calculated from the measured current in the DC link. Measurements were carried out utilizing dSpace-measurement software. The Converter software was used to measure the rotating speed of the permanent magnet synchronous machine (PMSM) and to estimate the motor torque. Two S-10 pressure sensors manufactured by WIKA were installed to measure the pressures at the pump outlet and between the 2/2-valve and cylinders. Yokogawa PZ4000 Power analyzers with a sampling time of $10 \mu$ s were used to measure the phase voltages and currents. The speed and height of the fork were measured by a wire-actuated encoder SGW/SGI from SIKO. HITEC Zero-Flux B 2000 current sensors were used. The accuracy of the sensors can be considered acceptable for these test purposes.

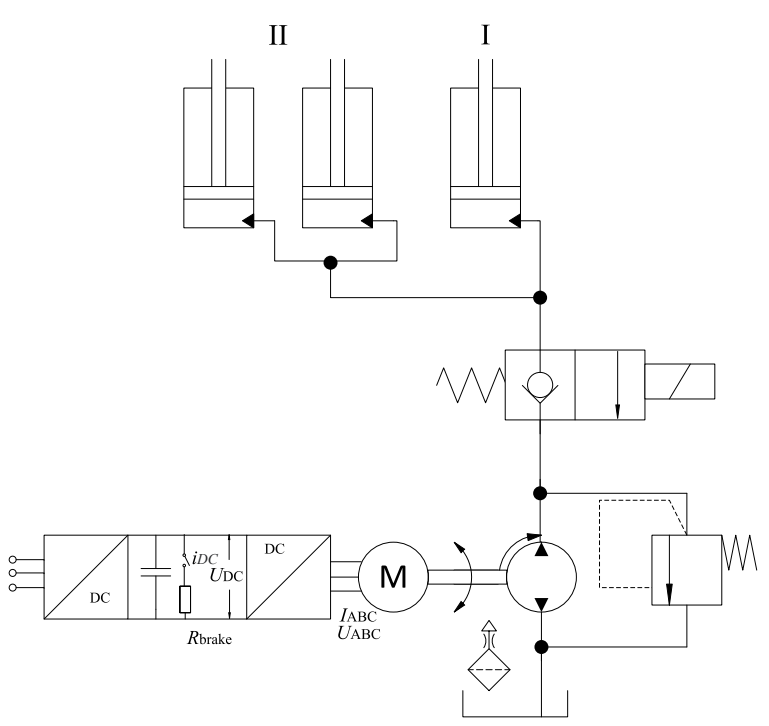

Fig. 1. Electric and hydraulic circuits of the main lift function with energy regeneration from potential energy; the experimental system consists of single-acting cylinder (I free lift zone, II second cylinder zone), two-way normally closed poppet valve, pressure relief valve, hydraulic pump/motor, oil tank, permanent magnet synchronous motor/generator, phase voltage and phase current probes, frequency converter and brake resistor $R_{\text {brake, }} D C$ voltage and DC current probes

\subsection{Hydraulic Recovery System Setup}

The hydraulic recovery setup is based on a fairly similar truck model, the Humanic HX-16. The simplified hydraulic system of the forklift is shown in Fig. 2. The main components in the studied energy recovery system are the pressure accumulators and the digital flow control unit (DFCU). The DFCU consists of two individually adjustable control edges 
containing five poppet-type on/off-valves each, all paired with differently sized orifices. The individual adjustability of the control edges is needed for the dynamic division of volume flows between the accumulator package and the tank.

A hydraulic accumulator is a device that stores pressurized hydraulic fluid with an internal nitrogen gas volume enabling the energy storing. The accumulators, manufactured by Hydroll with nominal size of 4 liters, used in this study are of a piston-type, which consist of oil and gas chambers separated from each other with a piston. The pre-load pressure level of the gas chamber determines the maximum energy content of the accumulator and affects the efficiency of the recovery. Thus, for efficient operation, the pressure level must be adjustable. The altering of preload pressure to a higher value between tests, when needed, was done utilizing an external gas container.

For operating the DFCU, a cost-function-based controller was built to determine which valves of the DFCU (both control edges) are to be opened and which closed in order to simultaneously perform the charging of the accumulators and provide the required lowering of velocity. The controller calculates the flow through the control edges using the data from the pressure transducers. For these calculations, the equation for turbulent flow through an orifice given by:

$$
q_{\mathrm{V}}=C_{\mathrm{q}} A \sqrt{\frac{2 \Delta p}{\rho}}
$$

is modified to:

$$
q_{\mathrm{V}}=K \cdot \Delta p^{z}
$$

The corresponding values of constants $K$ and $z$ are individually identified for each passage in the DFCU and adapted to the controller.

The identification was done by manually finding the values for the said constants in Eq. (2) to match the measured pressure difference - flow curve of each passage. This approach has been found to be a viable method for taking into to account both the turbulent losses in the orifice and in the valve, in addition to the partly laminar losses in the flow paths of each passage [21].

The recovered energy is utilized in the following lift phase by directing it to the pump inlet, thus reducing the pressure difference over the pump and thereby decreasing the power needs of the electric motor driving the pump.
The instrumentation of the test bench covers measurement devices for pressures, flows, temperatures, rotational speed, torque, load forces, load position, battery voltage, and current. In this study, however, the flow sensors were bypassed to achieve the full recovery potential of the system. The current transducer used was an LEM DH 500 B420L $\mathrm{B}$ and the load position was measured with a Waycon SX120-6000-420A-SA draw wire sensor. The energy consumption reduction results given in this paper were calculated from the measured battery voltage and current drawn from it. Measurements were carried out using Matlab/Simulink xPC Target software, which also included the controller for the DFCU.

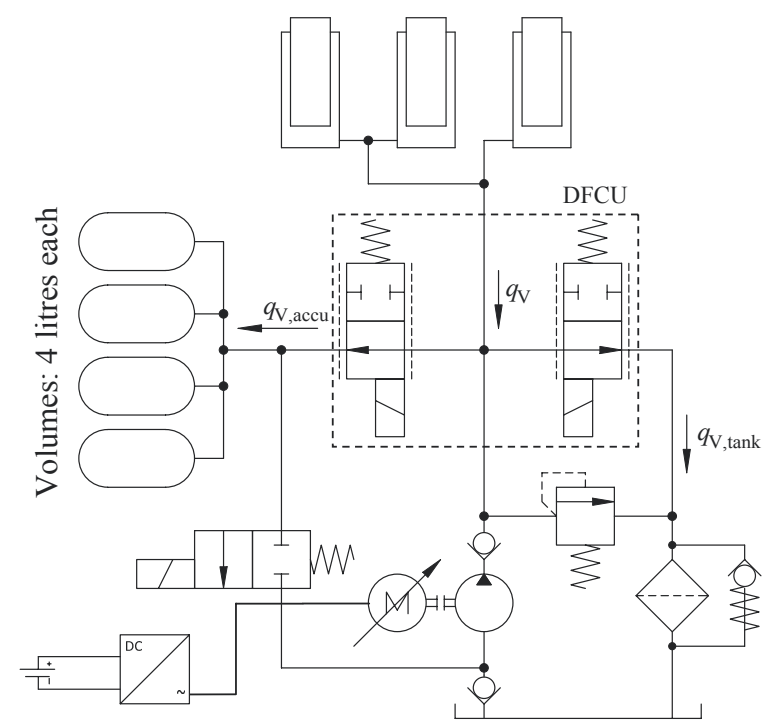

Fig. 2. Simplified circuit diagram of the hydraulic storage test system

\subsection{Description of Performed Tests}

The experimental setups were tested with payloads of 0,500 , and $1000 \mathrm{~kg}$ at different motor speeds. The velocities of the forks in both cases were set to $0.2,0.3$, and $0.4 \mathrm{~m} / \mathrm{s}$. The travel distance had to be limited to $1.6 \mathrm{~m}$ due to the maximum measurement time of 10 seconds with a sampling time of $10 \mu$ s of the Yokogawa PZ4000 Power analyzer in the electric recovery setup. The measurements were made in the free lift zone using the first cylinders of the telescopes, resulting in a low tare in this case. This was done in order to attain better correspondence between the pressure levels of the two systems, since the moving structural masses of the masts are fairly similar in free lift zone, but differ greatly in second cylinder zone.

For the electric recovery setup, lifting and lowering motions were measured separately due to 
limitations of used Power analyzer. For the hydraulic recovery setup, measurements for each measurement point were performed in a single cycle consisting of a continuous sequence of lifting, lowering and lifting phases. The first lift phase in the cycle is executed without assistance from the accumulators and the latter lift phase with the assistance of energy recovered during lowering phase.

\subsection{Detailed Information on Test Platforms}

Details on the main components of both test platforms are presented in Table 1.

Table 1. Main differences between platforms

\begin{tabular}{lcc}
\hline \multirow{2}{*}{ Parameter } & \multicolumn{2}{c}{ Test setup } \\
\cline { 2 - 3 } & Electric recovery & Hydraulic recovery \\
\hline $\begin{array}{l}\text { Theoretical volumetric } \\
\text { displacement of the } \\
\text { pump [m3/rev] }\end{array}$ & $\begin{array}{c}13.3 \cdot 10-6, \\
\text { manufactured } \\
\text { by Erker }\end{array}$ & $\begin{array}{c}19 \cdot 10-6, \\
\text { manufactured } \\
\text { by Parker }\end{array}$ \\
\hline Motor & $\begin{array}{c}\text { 10 kW CFM112M } \\
\text { PMSM manufactured } \\
\text { by Sew-eurodrives }\end{array}$ & $\begin{array}{c}14 \mathrm{~kW} \mathrm{IM} \\
\text { by Danaher }\end{array}$ \\
\hline $\begin{array}{l}\text { Converter } \\
\text { ACSM1-04x4) }-046 \mathrm{~A}-4 \text { by ABB }\end{array}$ & MHI 16A70-04020, \\
\hline $\begin{array}{l}\text { Piston: cross- } \\
\text { sectional area of the } \\
\text { free lift cylinder [m²] }\end{array}$ & 0.0026 & 0.0033 \\
\hline $\begin{array}{l}\text { Maximum stroke of } \\
\text { free lift cylinder [m] }\end{array}$ & 0.88 & 1.35 \\
\hline
\end{tabular}

\section{EVALUATION OF ENERGY UTILIZATION}

Before investigating any energy-saving system, it is necessary to discuss how to evaluate the utilization of energy in an electro-hydraulic forklift. This section introduces the definitions used for the evaluation of energy utilization in the test setups:

\subsection{Efficiency}

Efficiency as a function of time $\eta(t)$ is normally defined as a ratio between the output $\left(P_{\text {out }}\right)$ and input $\left(P_{\text {in }}\right)$ powers:

$$
\eta(t)=\frac{P_{\mathrm{out}}(t)}{P_{\mathrm{in}}(t)} .
$$

Even though the efficiency $\eta(t)$ is a function of time, it is normally measured while trying to keep $P_{\text {out }}$ and $P_{\text {in }}$ as constant as possible in a static situation in order to be able to obtain, for example, the rated efficiency of a motor without time dependence. Measuring of the rated efficiency of an electric motor normally takes several hours in order to reach the thermal equilibrium of the machine before defining the efficiency. In the case of a limited linear movement, however, it is very difficult to apply this definition of efficiency as there is no steady state in the operation. Even when abandoning the need to reach thermal equilibrium there is only a few seconds of constant speed operation at some "constant" efficiency, and thus, measuring efficiency becomes very difficult. In the case of a forklift, we are actually not very interested in the instantaneous efficiency of the system but in the ratio of the total output to input energies, which is how energy efficiency is defined.

\subsection{Energy Efficiency}

The energy efficiency $\eta_{\text {energy }}(t)$ for a time interval $\left[t_{1}, t_{2}\right]$ is defined as:

$$
\eta_{\text {energy }}(t)=\frac{\int_{t_{1}}^{t_{2}} P_{\text {out }}(t) \mathrm{d} t}{\int_{t_{1}}^{t_{2}} P_{\text {in }}(t) \mathrm{d} t}=\frac{E_{\text {out }}}{E_{\text {in }}},
$$

where $E_{\text {out }}$ is the total output energy and $E_{\text {in }}$ is the total input energy of the system during the time interval starting at $t_{1}$ and ending at $t_{2}$. Energy efficiency should normally be regarded as a comprehensive term taking the whole life cycle of the system into account. Therefore, the cycle efficiency is defined for each test setup. The calculation of energy efficiency is described in detail in [18] for the electric energy recovery setup and in [16] for the hydraulic recovery setup.

\subsection{Energy-Saving Ratio}

In order to compare the different test setup efficiencies, the energy-saving ratio $\Gamma_{\mathrm{s}}$ is defined as:

$$
\Gamma_{\mathrm{s}}=\frac{E_{\text {old }}-E_{\text {new }}}{E_{\text {old }}},
$$

where $E_{\text {old }}$ is the energy consumption of the forklift without energy recovery and $E_{\text {new }}$ is the energy consumption of the forklift with energy recovery. This ratio $\Gamma_{\mathrm{s}}$ describes how much energy can be saved when energy recovery is used.

The energy consumption $E_{\text {old }}$ of the electric drive forklift without energy recovery and $E_{\text {new }}$ energy 
consumption of the forklift with energy recovery for an electric recovery test setup is defined as:

$$
\begin{aligned}
& E_{\text {cycle_old }}=E_{\text {mot }} /\left(\eta_{\mathrm{SC}} \cdot \eta_{\text {inv }}\right), \\
& E_{\text {cycle_new }}=E_{\text {old }}-E_{\text {brake }} \cdot \eta_{\mathrm{SC}},
\end{aligned}
$$

where $E_{\text {mot }}$ is the input energy from the electric motor, $\eta_{\text {inv }}$ is the inverter efficiency, $E_{\text {brake }}$ is the recovered energy, and $\eta_{\mathrm{SC}}$ is the discharge efficiency of the supercapacitor, assuming that the charge efficiency is equal to the discharge efficiency. Therefore, the energy-saving ratio $\Gamma_{\mathrm{s}}$ can be defined for an electric recovery test setup as:

$$
\Gamma_{\mathrm{s}}=\frac{E_{\text {brake }} \cdot \eta_{\mathrm{SC}}}{E_{\text {cycle_old }}}=\frac{E_{\text {brake }} \cdot \eta_{\text {inv }} \eta_{\mathrm{CDSC}}}{E_{\text {mot }}} .
$$

The $\eta_{\mathrm{CDSC}}$ is the charge-discharge efficiency of the supercapacitor [4]. The inverter efficiency is assumed to be constant and equal to $95 \%$. The calculation of Ebrake and Emotor is described in detail in [19] for the electric energy recovery setup:

$$
\begin{gathered}
E_{\text {brake }}=\int_{t 1}^{t 2}\left(i_{\text {brake }}^{2} \cdot R_{\text {brake }}\right) \mathrm{d} t, \\
E_{\text {motor }}=\int_{t 1}^{t 2}\left(i_{\mathrm{a}} u_{\mathrm{a}}+i_{\mathrm{b}} u_{\mathrm{b}}+i_{\mathrm{c}} u_{\mathrm{c}}\right) \mathrm{d} t .
\end{gathered}
$$

For the hydraulic recovery test setup, $\Gamma_{\mathrm{s}}$ is defined as:

$$
\Gamma_{\mathrm{s}}=\frac{E_{\text {unassisted }}-E_{\text {assisted }}}{E_{\text {unassisted }}},
$$

where $E_{\text {assisted }}$ is the energy consumption (calculated from the measured electric power drawn from the battery pack) with the hydraulic assistance on and $E_{\text {unassisted }}$ is the energy consumption with the assistance off. The energy consumptions for both the assisted and unassisted cases are defined as:

$$
E=\int_{t_{0}}^{t_{1}} P \mathrm{~d} t=\int_{t_{0}}^{t_{1}}(U \cdot I) \mathrm{d} t
$$

where $U$ and $I$ are voltage and current, respectively.

Since the energies are calculated from discrete measurements, Eq. (12) is discretized to:

$$
\Delta E=\sum P \cdot \Delta t=\sum U \cdot I \cdot \Delta t
$$

where $\Delta t$ is the sampling interval.

\section{RESULTS}

This section reports the results obtained from the measurements described in the previous section. Tables 2 and 3 show the energy saving ratios for

\begin{tabular}{|c|c|c|c|}
\hline \multirow{2}{*}{$\begin{array}{l}\text { Fork's velocity } \\
\qquad[\mathrm{m} / \mathrm{s}]\end{array}$} & \multicolumn{3}{|c|}{ Load [kg] } \\
\hline & 0 & 500 & 1000 \\
\hline 0.4 & $0 \%$ * & $17 \%$ & $25 \%$ \\
\hline 0.3 & $0 \% *$ & $25 \%$ & $31 \%$ \\
\hline 0.2 & $0 \%$ ** & $34 \%$ & $36 \%$ \\
\hline
\end{tabular}
different fork's velocities and payloads for the electric and hydraulic recovery test setups, respectively. Fig. 3 below shows a graphical comparison of the energy saving ratios of the electric and hydraulic setup (Tables 2 and 3 (single pre-load pressure results)).

Table 2. Energy-savings ratios for different speeds and payloads for the electric recovery setup

Fig. 3 and Table 2 demonstrate the results obtained using only the free lift zone of the Humanic forklifts. This results in a low tare as the telescopic system is not lifted at all. In first case, the hydraulic recovery system is (Table 3, top section) optimized for each load and roughly for the travel distance. In the second case it is optimized to a one load/distance, and therefore is not optimal in any way for the other loads. Optimization for velocities was not conducted for any case. It should be noted that the energy saving ratio is high where an optimized hydraulic accumulator was used.

In Fig. 3, the hydraulic accumulator was optimized for the $500 \mathrm{~kg}$ payload and $1.6 \mathrm{~m}$ height. The direct hydraulic energy storage results in a good energy saving ratio in such a case. However, when the same settings are used for the $1000 \mathrm{~kg}$ mass, the electric energy storage system outperforms the hydraulic storage system by 5 to $14 \%$ with corresponding velocities of 0.4 to $0.2 \mathrm{~m} / \mathrm{s}$ (compare Tables 2 and 3).

In Table 3, the optimized pre-load pressure for the hydraulic accumulator gave good results for the 1000 $\mathrm{kg}$ case in the hydraulic storage system. However, if this setting is used, there will be no recovery in the case of a $500 \mathrm{~kg}$ mass, which shows the vulnerability of the direct hydraulic storage system when using varying loads and heights. 
Table 3. Energy saving ratios for different speeds and payloads for the hydraulic recovery setup

\begin{tabular}{cccc}
\hline $\begin{array}{c}\text { Fork's velocity } \\
{[\mathrm{m} / \mathrm{s}]}\end{array}$ & \multicolumn{3}{c}{ Load [kg] } \\
\cline { 2 - 4 } & 0 & 500 & 1000 \\
\hline Optimal pre-load pressure for each load [\%] \\
\hline 0.4 & 0 & 26 & 41 \\
\hline 0.3 & 0 & 30 & 42 \\
\hline 0.2 & 0 & 31 & 45 \\
\hline Single pre-load pressure (optimized for 500 kg) [\%] \\
\hline 0.4 & 0 & 26 \\
\hline 0.3 & 0 & 30 & 20 \\
\hline 0.2 & 0 & 31 & 20 \\
\hline
\end{tabular}

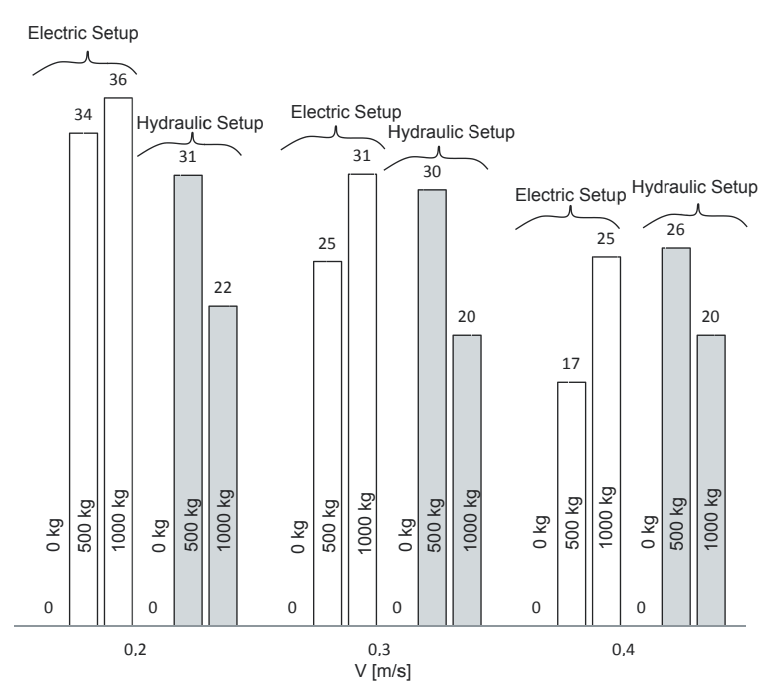

Fig. 3. Comparison of the energy-savings ratios in \% for the electric and hydraulic tests systems, (for hydraulic test setup results for a single pre-load pressure setup are shown), where $V$ is the fork's velocity

\section{DISCUSSION}

In this study, the target was to produce similar operating conditions for two slightly different forklift trucks. Considering the restraints and similarities of the two systems, the simplest solution was to run tests in the free lift zone, and to limit the travel distance to $1.6 \mathrm{~m}$. The relatively short travel distance favored the hydraulic setup by a few percent points in terms of saving ratios, since the hydraulic accumulator capacity in these tests is limited to 16 liters. The selection of the free lift zone instead of the second cylinder zone affected both of the systems by decreasing the achievable savings ratios.

\subsection{Results of the Electric Energy Storage System}

The results shown in Table 2 for the energy savings ratio of the electric recovery test setup seem low. The energy-savings ratio increases slightly with increasing load and decreasing speed. With a $0 \mathrm{~kg}$ load there was no recovery observed, and during lowering the electric machine was working in the motoring mode instead of generating mode. The maximum energy savings ratio in the free lift zone is $36 \%$. This is significantly less than earlier measurements achieved when operating in the second lifting zone of the forklift where the tare of the system is high and the relative hydro-mechanical losses of the system are lower [20]. According to [20], the maximum energy-saving ratio reached with this same Humanic forklift was 53\% when operating in the second lifting zone of the telescope with a 920 $\mathrm{kg}$ load. The mass of the moving parts of the mast is larger, which thereby enables the electric drive components to operate closer to their nominal values. There is significantly more potential energy to recover in the second cylinder zone than in the free lift zone.

\subsection{Results of the Hydraulic Storage System}

The measured energy savings ratios of the hydraulic recovery circuit ranged from 0 to $45 \%$. With no load, the system pressure levels remain too low for energy recovery, as in the previous case. This is due to the fact that the total flow losses of the system are in the range of cylinder pressure. By introducing a load, the recovery system becomes effective. Using loadoptimized pre-load pressures in the gas chambers of the accumulators, the measured energy saving ratios ranged from 26 to $31 \%$ and from 41 to $45 \%$ for loads of 500 and $1000 \mathrm{~kg}$, respectively. Considering the applicability of such a system with load optimized pre-load pressure, it is evident that the loads should remain relatively constant for sufficient durations. Such cases are numerous, for example, warehouses and material handling tasks in industry.

In mixed goods (variable loads) warehouses, it would not be advisable to alter the pre-load pressure between each lifting/lowering phase (because of the additional energy consumption in the form of pressurized gas) and, therefore, in most cases the pre-load pressure setting would not be optimal. The measurements indicate that when using a single preload pressure, optimized for a $500 \mathrm{~kg}$ load, the savings ratios with a $1000 \mathrm{~kg}$ load would drop significantly (to approximately $20 \%$ ) for the whole velocity range when compared with those using the optimal preload pressure. The effect of pre-load pressure setting on the effectiveness of the energy recovery system is analyzed in greater detail in [22]. In order to devise a hydraulic recovery system that performs better in mixed load situations the research group at Aalto 
University will design and construct an alternative recovery circuit based on a hydraulic transformer. Even though this new system is expected to have a lower peak efficiency (than the optimized direct system), simulations [13] suggest that it has a better overall efficiency.

\subsection{Differences in the Two Previous Systems}

It was observed that in the free lifting zone, the hydraulic recovery setup with its optimized pressure settings showed better results compared with the electric recovery setup. The less efficient behavior of the electric setup can be partly explained by the short travel distance $(1.6 \mathrm{~m})$, short time (max $5 \mathrm{~s})$ during which generator can recover the electric energy from the potential energy in the electric recovery setup and lower tare, which does not enable the electric drive components to operate closer to their nominal and efficient values.

\subsection{Operational Characteristics}

The hydraulic recovery system was designed to leave the operational characteristics unchanged and this was also achieved. The system can be used by adopting one of two different operation strategies in terms of pre-load pressure optimisation. Firstly, one could optimize the pressure level permanently for one load. This would be easier from the operator point of view, but the efficiency would not be optimal in most cases. The second strategy can be implemented if the parameters (load and height) for lifting and lowering are known in advance, if they remain relatively constant, and if their quantity is sufficient. In this strategy, the pre-load pressure is optimized to match the known upcoming cycle. This would allow the recovery system to operate at optimal efficiency, but as a drawback it would add an additional work phase, thus consuming energy.

The electric recovery system showed very good controllability of the hydraulics side. There are no limitations in the electric recovery setup as long as the electric energy storage selected is large enough to receive the largest possible amount of recovered energy during a single lowering action. With increasing electric machine torque (proportional to the sum of the payload and tare), the system efficiency increases because the electric drive components operate closer to their nominal and most efficient values [23] and [24].

\subsection{Other Observations}

To modify a conventional forklift to recover potential energy, the following actions are required:

For electric recovery: the control valve has to be replaced with a two-way normally closed valve; the traditional single-acting hydraulic pump has to be replaced with a hydraulic machine working in both directions; an energy storage, e.g. a supercapacitor bank, has to be added for storing the recovered energy, and the control software of the electric motor has to be updated. Lead-acid batteries can also be used, but supercapacitors have a higher charging efficiency.

Current electric recovery setup is operated with a high voltage up to $900 \mathrm{~V}$. It is considered a dangerous voltage level for mobile working machines. In the future, a detailed comparison with a low voltage $48 \mathrm{~V}$ safe setup will be studied. However, we anticipate that it might have similar results from the energy-savings point of view as the electric energy recovery system evaluated in this paper.

For direct hydraulic recovery: the hydraulic circuit has to be enhanced with an additional (leakage free) flow control unit and regeneration valve; a hydraulic accumulator(s) has to be added, a pump has to be altered to a type allowing pressurization of the inlet, and the software has to be updated to control the directions of oil flow.

An indirect hydraulic energy recovery system consisting of two controllable hydraulic machines and a hydraulic accumulator could also be implemented, but its behaviour was not studied here. However, we anticipate that it might have similar capabilities as the electric energy control system evaluated in this paper.

\section{CONCLUSIONS}

The presented work concentrated on analysing the possibilities of using energy regeneration in electrohydraulic forklift systems. The measurements showed that energy recovery from potential energy is possible in both hydraulic and electric energy storage applications. According to the results, the maximum energy-savings ratio for the free lift zone with optimized hydraulic accumulator parameters was $45 \%$ using the direct hydraulic recovery setup. In practice, however, the direct system suffers from the need to control the pre-load pressure of the hydraulic accumulator or the requirement to select a fixed value for the pre-load pressure, and, as a result, significantly lower average values may be obtained. In this test, the best energy-savings ratio of the electric recovery setup was $36 \%$. This result is disappointingly low compared 
with the previous results, obtained when operating in the second cylinder zone of the same truck [19]. It can be concluded that the test arrangement favoured the direct hydraulic recovery system, but it also shows that the electric drive system has numerous advantages. The latter does not require any pre-load settings and tunings of the energy storage for a specific load or lifting height. Therefore, the direct hydraulic recovery approach is impractical in cases where the lifting and lowering range and the mass vary. In such cases, an electric or indirect hydraulic energy recovery system should be considered instead.

\section{ACKNOWLEDGEMENTS}

Hydraulic recovery studies; This study is connected to the MIDE/HybLab project, funded by Aalto University. The cooperation of Jyri Juhala, M.Sc. at the Department of Engineering Design and Production of the School of Engineering of Aalto University is highly appreciated.

Electric recovery studies; The research was enabled by the financial support of Tekes, the Finnish Funding Agency for Technology and Innovation and FIMA (Forum for Intelligent Machines), the European Union, the European Regional Development Fund, and the Regional Council of South Karelia. The research was carried out at the Institute of Energy Technology, Department of Electrical Engineering, Lappeenranta University of Technology, Lappeenranta, Finland.

\section{REFERENCES}

[1] Liang, X. (2002). On Improving Energy Utilization in Hydraulic Booms. PhD thesis, Espoo.

[2] Lin, T., Wang, Q., Hu, B., Gong, W. (2010). Development of hybrid powered hydraulic construction machinery. Journal Automation in Construction, vol. 19, no. 1, p. 11-19, DOI:10.1016/j.autcon.2009.09.005.

[3] Nyman, J., Rydberg, K. (2001). Energy saving lifting hydraulic systems. Proceedings of the 7th Scandinavian International Conference on Fluid Power, Linköping.

[4] Nyman, J., Bärnström, J., Rydberg, K. (2003). Use of accumulators to reduce the need of electric power in hydraulic lifting systems. Proceedings of the $8^{\text {th }}$ Scandinavian International Conference on Fluid Power, Tampere.

[5] Ming, X., Bo, J., Guojin, C., Jing, N. (2013). Speed-control of energy regulation based variable-speed electrohydraulic drive. Strojniški vestnik - Journal of Mechanical Engineering, vol. 59 , no. $7-8$, p. 433-442, DOI:10.5545/svjme.2012.911.

[6] Wang, D., Guan, C., Pan, S., Zhang, M., Lin, X. (2009). Performance analysis of hydraulic excavator powertrain hybridization. Journal Automation in Construction, vol. 18, no. 3, p. 249-257, DOI:10.1016/j.autcon.2008.10.001.

[7] Sun, W., Virvalo, T. (2003). Accumulator-pumpmotor as energy saving system in hydraulic boom. Proceedings of the $8^{\text {th }}$ Scandinavian International Conference on Fluid Power, Tampere.

[8] Andersen, T., Hansen, M., Pedersen, H. (2005). Regeneration of potential energy in hydraulic forklift trucks. Proceedings of The $6^{\text {th }}$ International Conference on Fluid Power Transmission and Control, Hangzhou.

[9] Hänninen, H., Juhala, J., Sinkkonen, A., Hentunen, A., Pietola, M. (2010). Comparing hybrid power transmission systems of work machines. Proceedings of the $7^{\text {th }}$ International Fluid Power Conference, Aachen.

[10] Minav, T., Virtanen, A., Laurila, L., Pyrhönen, J. (2012). Storage of energy recovered from an industrial forklift. Journal Automation in Construction, vol. 22, p. 506-515, DOI:10.1016/j.autcon.2011.11.010.

[11] Lin, T., Wang, Q., Hu, B., Gong, W. (2010). Research on the energy regeneration systems for hydraulic excavators. Journal Automation in construction, vol. 19, no. 8, p. 1016-1026, DOI:10.1016/j.autcon.2010.08.002.

[12] Hui, S., Junqing, J. (2010). Research on the system configuration and energy control strategy for parallel hydraulic hybrid loader. Journal Automation in Construction, vol. 19, no. 2, p. 213-220, DOI:10.1016/j.autcon.2009.10.006.

[13] Yang, H., Sun, W., Xu, B. (2007). New investigation in energy regeneration of hydraulic elevators. IEEE/ASME Transactions on Mechatronics Journal, vol. 12, no. 5, p. 519526, DOI:10.1109/TMECH.2007.905691.

[14] Ho, T.H., Ahn, K.K. (2008). Design and control of a closed-loop hydraulic energy-regenerative system. Journal Automation in Construction, vol. 17, p. 361-367.

[15] Xiao, Q., Wang, Q., Zhang, Y. (2008). Control strategies of power system in hybrid hydraulic excavator. Journal Automation in Construction, vol. 17 , no. 4, p. 361-367, DOI:10.1016/j. autcon.2007.05.014. 
[16] Sinkkonen, A., Kauranne, H., Hänninen, H., Pietola, M. (2011). Analysis of energy balance in electrohydraulic forklift. Proceedings of the $12^{\text {th }}$ Scandinavian International Conference on Fluid Power, Tampere.

[17] Juhala, J., Kauranne, H., Kajaste, J., Pietola, M. (2009). Improving energy efficiency of work machine with digital hydraulics and pressure accumulator. Proceedings of the 11th Scandinavian International Conference on Fluid Power, Linköping.

[18] Minav, T. Immonen, P., Laurila, L., Vtorov, V., Pyrhönen, J., Niemelä, M. (2011). Electric energy recovery system for a hydraulic forklift - theoretical and experimental evaluation. IET Electric Power Applications, vol. 5, no. 4, p. 377-385, DOI:10.1049/iet-epa.2009.0302.

[19] Charging Lead Acid. (2012). from http:// batteryuniversity.com/learn/article/charging the_lead_acid_battery, accessed on 10.01.2012.

[20] Minav, T. (2011). Electric-Drive-Based Control and Electric Energy Regeneration in a Hydraulic System. PhD thesis, Lappeenranta University of Technology, Lappeenranta.

[21] Linjama, M., Huova, M., \& Karvonen, M. (2012). Modelling of flow characteristics of on/ off valves. The 5th Workshop on Digital Fluid Power, Tampere.

[22] Hänninen, H., Kajaste, J., Pietola, M. (2012). Optimizing hydraulic energy recovery system of reach truck. Fluid Power and Motion Control, Bath, p.109-121.

[23] Minav, T., Laurila, L., Pyrhönen, J., Vtorov, V. (2011). Direct pump control effects on the energy efficiency in an electro-hydraulic lifting system. Journal International Review of Automatic Control, vol. 4, no. 2, p. 235-242.

[24] Minav, T., Laurila, L., Pyrhönen, J. (2012). Permanent magnet synchronous machine sizing: effect on the energy efficiency of an electro-hydraulic forklift. IEEE Transactions on Industrial Electronics, vol. 59, no. 6, p. 24662474, DOI:10.1109/TIE.2011.214868. 